\title{
Antiangiogenic treatment in hepatocellular carcinoma: the balance of efficacy and safety
}

This article was published in the following Dove Press journal:

Cancer Management and Research

16 October 2013

Number of times this article has been viewed

\section{Martin-Walter Welker Joerg Trojan}

Medizinische Klinik I, Universitätsklinikum Frankfurt, Germany
Correspondence: Joerg Trojan Medizinische Klinik I,

Universitätsklinikum Frankfurt,

Theodor-Stern-Kai 7, Frankfurt

60590, Germany

Tel +496963017860

Fax +4969630I 6448

Email trojan@em.uni-frankfurt.de
Abstract: Hepatocellular carcinoma (HCC) is a severe complication of advanced liver disease with a worldwide incidence of more than 600,000 patients per year. Liver function, clinical performance status, and tumor size are considered in the Barcelona Clinic Liver Cancer (BCLC) system. While curative treatment options are available for early stages, most patients present with intermediate- or advanced-stage HCC, burdened with a poor prognosis, substantially influenced by the degree of liver-function impairment. Hypervascularization is a major characteristic of HCC, and antiangiogenic treatments are the basis of treatment in noncurative stages, including interventional and pharmacological treatments. Currently, the tyrosine-kinase inhibitor sorafenib is still the only approved drug for HCC. Further improvements in survival in patients with intermediate- and advanced-stage HCC may be anticipated by both multimodal approaches, such as combination of interventional and systemic treatments, and new systemic treatment options. Until now, the Phase III development of other tyrosine-kinase inhibitors in patients with advanced HCC has failed due to minor efficacy and/or increased toxicity compared to sorafenib. However, promising Phase II data have been reported with MET inhibitors in this hard-to-treat population. This review gives a critical overview of antiangiogenic drugs and strategies in intermediate- and advanced-stage HCC, with a special focus on safety.

Keywords: HCC, sorafenib, antiangiogenesis, TACE, MET

\section{Introduction}

The worldwide incidence of hepatocellular carcinoma (HCC) exceeds 600,000 patients per year, and is still rising. ${ }^{1}$ An important characteristic of $\mathrm{HCC}$ is the predominant occurrence in liver cirrhosis and advanced chronic liver disease. ${ }^{1}$ This explains why overall prognosis remains poor, as survival may depend on impaired liver function rather than tumor progression in some patients, and therapeutic options often are limited by potential hepatotoxicity. ${ }^{1,2}$

The Barcelona Clinic Liver Cancer (BCLC) therapeutic algorithm takes this into account by combining tumor stage, clinical performance status, and liver function to stratify prognosis and treatment. ${ }^{3,4}$ Early stages (BCLC 0 and BCLC A) are characterized by limited tumor size and preserved liver function, while intermediate- (BCLC B), advanced- (BCLC C), and end-stage (BCLCD) cancer are defined by extended tumor size and decreased liver function. Consequently, surgical (resection or transplantation) or percutaneous thermal therapies (radiofrequency or microwave ablation) are mainly considered suitable for the early stage, while interventional therapies (transarterial chemo- or radioembolization) are applied in patients with intermediate-stage HCC. Systemic treatment with the tyrosine-kinase inhibitor sorafenib is considered the 
treatment of choice for patients with advanced-stage HCC. Patients with BCLC stage D do not benefit from cancer treatment, and thus are being considered for best supportive care only. Thus, recent strategies have focused on the establishment of new drugs for patients with advanced-stage HCC. Moreover, selected current trials focus on adjuvant pharmacological treatment options in early stage HCC or combination of interventional therapies and sorafenib in intermediate-stage HCC.

The development of efficient new drugs in HCC is challenged by the need for a safety profile, defined by low or absent hepatotoxicity and nephrotoxicity. Moreover, putative accumulation of the agent and its metabolites in patients with impaired liver and/or kidney function has to be taken into account and must be avoided.

Theoretically, HCC should be prone to inhibition of angiogenesis because it is a highly vascular tumor, and hypervascularization is an essential characteristic of HCC, closely linked to carcinogenesis and progression. ${ }^{5-7}$ Indeed, antiangiogenic treatment of HCC, either by mechanical destruction of arterial tumor vessels after transarterial chemoembolization (TACE) or by pharmacological inhibition with the dualkinase inhibitor sorafenib, which is still the only systemic agent approved for $\mathrm{HCC}$, is the current basis of noncurative approaches in HCC. ${ }^{8-12}$ So far, antiangiogenic tyrosine-kinase inhibitors other than sorafenib have failed in randomized placebo-controlled pivotal trials, due to either minor efficacy or unacceptable toxicity profiles. This review gives a critical overview of established antiangiogenic drugs and those currently being developed, and strategies with special focus on safety in intermediate- and advanced-stage HCC.

\section{Angiogenesis in liver cirrhosis and HCC}

Angiogenesis is closely related to chronic hepatitis and hepatic fibrogenesis, which in turn may lead to liver cirrhosis and HCC. The vascular endothelial growth-factor (VEGF) pathway was identified as the major driver in tumor angiogenesis. However, activation and/or upregulation of abundant proangiogenic signaling pathways may lead to resistance to VEGFbased antiangiogenic therapy, reinducing tumor angiogenesis and subsequently resulting in tumor progression. ${ }^{5}$ VEGF is crucially involved in angiogenesis, as well as in fibrogenesis in chronic liver disease, but other cytokines, growth factors, and metalloproteinases are additionally involved in these processes. ${ }^{13} \mathrm{HCC}$ nodules larger than $2 \mathrm{~cm}$ typically show early arterial enhancement, a surrogate of hypervascularization, which is pathognomonic for HCC. ${ }^{6,7}$ In patients with $\mathrm{HCC}$, higher VEGF serum levels were associated with poor outcome in the majority of but not all studies addressing this issue. ${ }^{14-19}$ Moreover, increased expression of angiopoietin 1/2 messenger RNA in tumor tissue, another proangiogenic factor, has been reported in patients with $\mathrm{HCC}^{20}$ Therefore, it may be concluded that angiogenesis in $\mathrm{HCC}$ is a complex process and most likely heterogeneous.

\section{Sorafenib in advanced hepatocellular carcinoma}

The proof of concept that pharmacological inhibition of angiogenesis is clinically meaningful in HCC was provided by four clinical trials showing consistently a survival benefit of approximately 3 months in patients with advanced HCC and preserved liver function treated with sorafenib, which is still the only systemic agent approved for advanced HCC. ${ }^{21-24}$ Sorafenib is a multikinase inhibitor with activity against VEGF receptor (VEGFR)-2, platelet-derived growth-factor receptor (PDGFR), receptor of the tyrosine kinase c-Kit, rapidly accelerated fibrosarcoma B kinase, and mitogen-activated protein kinase p38 signal-transduction pathways, which seem to be involved in the pathogenesis of $\mathrm{HCC}^{8}$ The main effect of sorafenib is disease stabilization, and sorafenib can be used with an acceptable safety profile under daily practice conditions. ${ }^{25,26}$ However, adverse effects - mainly fatigue, diarrhea, and hand-foot syndrome - may significantly alter quality of life and may lead to dose reduction of sorafenib. ${ }^{21-26}$ Within a recent Phase II study, dose escalation of sorafenib was not superior to best supportive care in patients with advanced HCC and disease progression during sorafenib $400 \mathrm{mg}$ twice daily, while adverse events (diarrhea $80 \%$, weight loss $75 \%$, fatigue $67 \%$, hand-foot skin reaction $49 \%$, abdominal pain $37 \%$, stomatitis $26 \%$ ) were common. ${ }^{27}$

\section{Antiangiogenic drugs in clinical development}

A consequent step of antiangiogenic drug development was to investigate tyrosine-kinase inhibitors with other or additional targets than sorafenib in HCC. Sunitinib, a tyrosine-kinase inhibitor targeting the tyrosine kinase Kit, PDGFR- $\alpha$ and $-\beta$, and VEGFR1, -2, and -3, was compared to sorafenib as firstline treatment of advanced HCC in the SUN1 170 trial. ${ }^{28}$ This trial was terminated early because of a higher rate of drugrelated adverse events in the sunitinib arm, including fatal outcomes. Overall survival in patients taking sunitinib was 7.9 months compared to 10.2 months in the sorafenib arm. Linifanib, a selective VEGFR and PDGFR tyrosine-kinase inhibitor, was also investigated in first-line treatment of 
advanced HCC compared to sorafenib. ${ }^{29}$ Linifanib was less effective than sorafenib, with a median overall survival of 9.1 months compared to 9.8 months in the sorafenib arm. A comparison of overall survival in current head-to-head Phase III studies investigating sorafenib, sunitinib, brivanib, linifanib, and erlotinib is given in Figure 1.

Recently, it was shown that inhibition of the fibroblast growth-factor receptor (FGFR)-4 pathway is involved in HCC development in a mouse model..$^{30}$ Brivanib, a selective dual inhibitor of VEGFR and FGFR, ${ }^{31}$ was shown to have antitumor activity in patients with advanced HCC in two open-label Phase II studies..$^{32,33}$ Unfortunately, brivanib was not superior compared to placebo in patients after sorafenib-treatment failure or intolerance to sorafenib in a Phase III study. ${ }^{34}$ In another Phase III trial comparing brivanib and sorafenib as first-line treatment in advanced HCC, brivanib failed to prove noninferiority in comparison to sorafenib. Moreover, serious adverse events were common in both the brivanib (59\%) and sorafenib (52\%) treatment arms. ${ }^{35}$ Therefore, the development of brivanib in HCC was stopped. Of note, the combination of sorafenib and the EGFR inhibitor erlotinib was not superior to sorafenib alone in terms of progression-free or overall survival. ${ }^{1}$ Moreover, the toxicity profile of this combination was worse than that of sorafenib alone. The results of recent clinical trials in advanced HCC are summarized in Table 1.

\section{Toxic effects of antiangiogenic therapy in HCC}

Based on the clinical trial experience of the last few years with antiangiogenic agents in HCC, certain "class" toxicity profiles have emerged. In HCC, as in other malignancies, these include hypertension, bleeding, thromboembolic events, and proteinuria. Some toxic effects are more specific for tyrosine-kinase inhibitors, eg, hand-foot skin reaction, rash, and diarrhea. In addition, a general problem of antiangiogenic agents in HCC is the risk of worsening liver function, which might result in liver-enzyme elevation and fatigue, and more importantly in jaundice, hepatic encephalopathy, and ascites.

With sorafenib, these side effects are manageable. ${ }^{21-24}$ However, especially in "dirty" kinase inhibitors, such as sunitinib, liver-specific toxicity seems to be even more prominent. ${ }^{28}$ Therefore, a goal of future development of antiangiogenic agents in HCC is a manageable side-effect profile with a low incidence of liver-related toxicity.

\section{Transarterial chemoembolization as antiangiogenic treatment}

Hepatic tissue hypoxemia, amongst others, seems to be a relevant trigger for angiogenesis in chronic liver disease via induction of VEGF. ${ }^{36}$ TACE was introduced into treatment algorithms for intermediate-stage HCC years before the approval of sorafenib. TACE may lead to reduction of tumor vascularization and viable tumor volume in $\mathrm{HCC},{ }^{37,38}$ and response to TACE is higher in patients with lower baseline VEGF serum levels. ${ }^{39}$ Increased expression of VEGF after TACE has been reported, and development of satellite HCC nodules adjacent to TACE-treated lesions is a known clinical problem. ${ }^{40-43}$ TACE-induced hypoxemia may therefore trigger the expression of angiogenic factors, ultimately resulting in

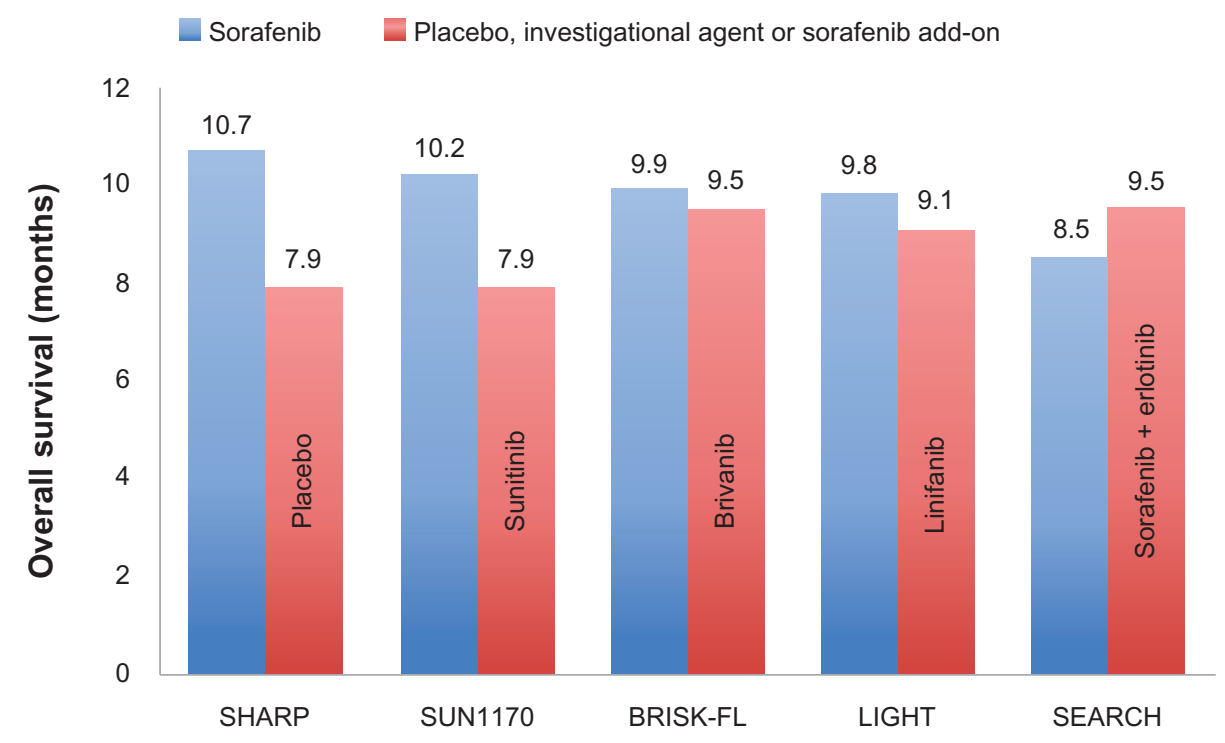

Figure I Overall survival in patients with advanced hepatocellular carcinoma treated with sorafenib (all studies, including the pivotal SHARP trial), ${ }^{21}$ sunitinib (SUNI I70 trial), ${ }^{28}$ brivanib (BRISK-FL trial), linifanib, (LIGHT trial), ${ }^{29}$ and sorafenib plus erlotinib (SEARCH trial), ${ }^{135}$ according to current head-to-head Phase III studies. 
Table I Efficacy of systemic targeted monotherapy in hepatocellular carcinoma according to current Phase I-III studies

\begin{tabular}{|c|c|c|c|c|c|c|c|c|}
\hline Author & Year & Phase & $\begin{array}{l}\text { Investigational } \\
\text { drug }\end{array}$ & $\mathbf{n}$ & $\mathbf{R R}$ & DCR & PFS/TTP & OS \\
\hline O’Neil et $\mathrm{a}^{68, \mathrm{a}}$ & 2009 & II & AZD 6244 & 16 & 0 & 37.5 & $\mathrm{nr}$ & $\mathrm{nr}$ \\
\hline Schwartz et $a^{69, b}$ & 2006 & II & Bevacizumab & 30 & 6.7 & 57 & $\mathrm{nr} / 6.4$ & $\mathrm{nr}$ \\
\hline Siegel et $\mathrm{al}^{70, \mathrm{~b}}$ & 2008 & ॥ & Bevacizumab & 46 & 13 & 65 & $6.9 / \mathrm{nr}$ & 12.4 \\
\hline Boige et $\mathrm{al}^{71}$ & 2012 & II & Bevacizumab & 43 & 14 & 42 & $\mathrm{nr}$ & $\mathrm{nr}$ \\
\hline Kim et $\mathrm{a}^{72}$ & 2012 & II & Bortezomib & 35 & 4 & 37 & $\mathrm{nr} / \mathrm{l} .6$ & 6.0 \\
\hline Park et $\mathrm{al}^{33}$ & 2011 & II & Brivanib & 55 & 7.2 & 47.2 & 2.7 & 10.0 \\
\hline Finn et $\mathrm{al}^{32}$ & 2012 & ॥ & Brivanib & 46 & 4.3 & 45.7 & $\mathrm{nr} / 2.7$ & 9.8 \\
\hline Johnson et $\mathrm{al}^{35}$ & 2012 & III & Brivanib & I, I55 (577 brivanib) & 12 & 66 & $\mathrm{nr} / 4.2$ & 9.9 \\
\hline Llovet et $\mathrm{al}^{34}$ & 2012 & III & Brivanib & 395 (263 brivanib) & 11.5 & 71.2 & $\mathrm{nr} / 4.2$ & 9.4 \\
\hline Gruenwald et $\mathrm{al}^{73}$ & 2007 & II & Cetuximab & 27 & 0 & 44 & $2.0 / 1.9$ & $\mathrm{nr}$ \\
\hline Zhu et $\mathrm{al}^{74}$ & 2007 & II & Cetuximab & 30 & 0 & 17 & $\mathrm{I} .4 / \mathrm{nr}$ & 9.6 \\
\hline Philip et $\mathrm{a}^{75}$ & 2005 & ॥ & Erlotinib & 38 & 9 & 50 & $3.2 / \mathrm{nr}$ & 13.0 \\
\hline Thomas et $\mathrm{al}^{76}$ & 2007 & II & Erlotinib & 40 & 0 & 43 & $3.1 / \mathrm{nr}$ & $6.25(10.75)^{c}$ \\
\hline Shiah et a ${ }^{17}$ & 2013 & 1 & Everolimus & 39 & $\mathrm{nr}$ & $44.4 / 7 I .4^{\mathrm{d}}$ & $\mathrm{nr}$ & $\mathrm{nr}$ \\
\hline Zhu et $\mathrm{al}^{78}$ & 2011 & $\mid / I I$ & Everolimus & 25 & 4 & 44 & $3.8 / \mathrm{nr}$ & 8.4 \\
\hline O'Dwyer et al $7^{79}$ & 2006 & ॥ & Gefitinib & 31 & 3 & 22.5 & $2.8 / \mathrm{nr}$ & 6.5 \\
\hline Lin et $\mathrm{a}^{80}$ & 2008 & II & Imatinib & 15 & 0 & 13.3 & $\mathrm{nr} / \mathrm{nr}$ & $\mathrm{nr}$ \\
\hline Bekaii-Saab et $\mathrm{al}^{81}$ & 2009 & II & lapatinib & 26 & 0 & 40 & $1.9 / \mathrm{nr}$ & 12.6 \\
\hline Ramanathan et $\mathrm{a}^{82}$ & 2009 & II & lapatinib & 40 & 5 & 35 & $2.3 / \mathrm{nr}$ & 6.2 \\
\hline Toh et $\mathrm{al}^{83}$ & 2013 & ॥ & linifanib & 44 & 9.1 & $\mathrm{nr}$ & $\mathrm{nr} / 3.7$ & 9.4 \\
\hline Cainap et $\mathrm{al}^{29}$ & 2013 & III & linifanib & I,035 (I:I randomization) & $\mathrm{nr}$ & $\mathrm{nr}$ & $\mathrm{nr} / 5.4$ & 9.1 \\
\hline Rizell et $\mathrm{al}^{84}$ & 2008 & II & Sirolimus & 21 & 4.8 & 23.8 & $\mathrm{nr} / \mathrm{nr}$ & 6.5 \\
\hline Furuse et $\mathrm{a}^{23}$ & 2008 & I & Sorafenib & 27 & 4 & 83 & $\mathrm{nr} / 4.9$ & 15.6 \\
\hline Abou-Alfa et a ${ }^{22}$ & 2006 & ॥ & Sorafenib & 137 & 2.2 & 33.6 & $\mathrm{nr} / 4.2$ & 9.2 \\
\hline Yau et $\mathrm{al}^{24}$ & 2009 & II & Sorafenib & 51 & 8 & 18 & $3.0 / \mathrm{nr}$ & 5.0 \\
\hline Llovet et $\mathrm{al}^{21}$ & 2008 & III & Sorafenib & 602 (299 sorafenib) & 2.0 & 71 & $\mathrm{nr} / 5.5$ & 10.7 \\
\hline Cheng et $\mathrm{a}^{85}$ & 2009 & III & Sorafenib & 226 (I50 sorafenib) & 3.3 & 54 & $\mathrm{nr} / 2.8$ & 6.5 \\
\hline Kudo et $\mathrm{al}^{86}$ & 2011 & III & Sorafenib & 458 (229 sorafenib) & $\mathrm{nr}$ & $\mathrm{nr}$ & $\mathrm{nr} / 5.4^{\mathrm{e}}$ & 29.7 \\
\hline Hoda et $\mathrm{a}^{87}$ & 2008 & II & Sunitinib & 23 & 6 & 35 & $\mathrm{nr} / \mathrm{nr}$ & $\mathrm{nr}$ \\
\hline Zhu et al ${ }^{88}$ & 2009 & II & Sunitinib & 34 & 2.9 & 47 & $3.9 / 4.1$ & 9.8 \\
\hline Faivre et a ${ }^{89}$ & 2009 & II & Sunitinib & 37 & 2.7 & 35 & $3.7 / 5.3$ & 8.0 \\
\hline Koeberle et al ${ }^{90}$ & 2010 & $\|$ & Sunitinib & 45 & 2 & 40 & $2.8 / 2.8$ & 9.3 \\
\hline Wörns et al $^{91}$ & 2010 & ॥ & Sunitinib & 11 & $\mathrm{nr}$ & 40 & $\mathrm{nr} / 3.2$ & 8.4 \\
\hline Barone et $\mathrm{a}^{92}$ & 2013 & II & Sunitinib & 34 & 11.8 & 44.1 & $\mathrm{nr} / 2.8$ & 5.8 \\
\hline Cheng et $\mathrm{a}^{28, \mathrm{a}}$ & 2011 & III & Sunitinib & I,073 (529 sunitinib) & $\mathrm{nr}$ & $\mathrm{nr}$ & $3.6 / 4.1$ & 8.1 \\
\hline Pinter et $\mathrm{al}^{93}$ & 2008 & $\mathrm{I} / \mathrm{II}$ & Thalidomide & 28 & 0 & 7.1 & $\mathrm{nr}$ & 5.1 \\
\hline Santoro et $\mathrm{al}^{94}$ & 2013 & 1 & Tivantinib & 21 & 0 & 45 & $\mathrm{nr} / 3.3$ & $\mathrm{nr}$ \\
\hline Santoro et al ${ }^{95}$ & 2013 & ॥ & Tivantinib & I07 (7I tivantinib) & 3 & 44 & $1.5 / 1.6$ & 6.6 \\
\hline Kanai et $\mathrm{al}^{96}$ & 2010 & $\mid / / I$ & TSU-68 & 35 & 8.6 & 42.8 & $\mathrm{nr} / 2 . \mathrm{I}$ & 13.1 \\
\hline Hsu et al ${ }^{97}$ & 2012 & $\|$ & Vandetanib & 90 (67 vandetanib) & 0 & $16.0 ; 5.3^{f}$ & I.7; I. $\left.\right|^{f}$ & $5.75 ; 5.95^{f}$ \\
\hline
\end{tabular}

Notes: a Trial stopped; boverlap of patient cohorts cannot be excluded from information provided; 'recorded from therapy start (recorded from diagnosis); dfor weekly and daily treated cohorts, respectively; enly patients with advanced HCC and response to TACE were included, and TTP did not differ significantly between sorafenib and placebo; ffor vandetanib 100 or $300 \mathrm{mg}$, respectively. For a better comparison of study results, efficacy according to RECIST criteria is given, as some studies used RECIST and some RECIST and modified RECIST criteria.

Adapted from Welker and Trojan. ${ }^{67}$

Abbreviations: DCR, disease-control rate (complete response + partial response + stable disease [\%]); OS, overall survival (months) - may differ between studies with respect to start point (start of therapy/diagnosis); PFS/TTP, progression-free survival/time to progression (months); RR, response rate (complete + partial response [\%]); nr, not reported; TACE, transcatheter arterial chemoembolization; RECIST, Response Evaluation Criteria in Solid Tumors trial; HCC, hepatocellular carcinoma.

tumor progression. ${ }^{40-44}$ These observations form the rationale for combining TACE - or other trans-arterial treatments with sorafenib, in order to prevent upregulation of VEGF. Several trials using a combination of sorafenib with lipiodolbased TACE, doxorubicin-eluting beads (DEB)-TACE, and selective internal radiation therapy (SIRT) have been reported (Table 2). The combination of sorafenib and TACE seems favorable in a subgroup of patients, but current data are controversial. ${ }^{45-54}$ In a recent meta-analysis, the efficacy of DEB-TACE was reported to be comparable to lipiodol-based TACE. ${ }^{55}$ The combination of sorafenib with DEB-TACE showed promising results in a Phase II trial. ${ }^{56}$ However, in the SPACE trial, [A Phase II Randomized, Doubleblind, Placebo-controlled Study of Sorafenib or Placebo in 
Table 2 Efficacy of sorafenib and TACE or SIRT in hepatocellular carcinoma (sequential therapy not included), according to current Phase I and II studies

\begin{tabular}{|c|c|c|c|c|c|c|c|}
\hline Author & Year & Phase & Investigational drug & $\mathbf{n}$ & $\mathbf{R R}$ & DCR & OS \\
\hline Britten et $\mathrm{al}^{98}$ & 2012 & I & Bevacizumab + TACE & 30 (I5 bevacicumab) & $\mathrm{nr}$ & $\mathrm{nr}$ & 49 \\
\hline Buijs et al ${ }^{99}$ & 2013 & ॥ & Bevacizumab + TACE & 25 & 60 & 100 & 10.8 \\
\hline Pawlik et al ${ }^{100}$ & 2011 & II & Sorafenib + DEB-TACE & 35 & 58 & 100 & $\mathrm{nr}$ \\
\hline Cabrera et $\mathrm{al}^{101}$ & 2011 & II & Sorafenib + DEB-TACE or SIRT & 47 & 56.1 & 68.2 & 18.5 \\
\hline Lencioni et $\mathrm{al}^{57}$ & 2012 & ॥ & Sorafenib + DEB-TACE & 307 (I54 sorafenib) & $\mathrm{nr}$ & $\mathrm{nr}$ & $\mathrm{nt}$ \\
\hline Chow et al ${ }^{102}$ & 2010 & II & Sorafenib + SIRT & 35 & 31.4 & 77.1 & 10.8 \\
\hline Dufour et al ${ }^{54}$ & 2010 & I & Sorafenib + TACE & 14 & $\mathrm{nr}^{\mathrm{a}}$ & $\mathrm{nr}^{\mathrm{a}}$ & $\mathrm{nr}^{\mathrm{a}}$ \\
\hline Erhardt et al ${ }^{103}$ & 2011 & II & Sorafenib + TACE & 45 & 2 & 77.8 & 18.5 \\
\hline Wu et al ${ }^{104}$ & 2012 & II & Sorafenib + TACE & 35 & 45.7 & 81.8 & $\mathrm{nr}$ \\
\hline Qu et $\mathrm{al}^{49}$ & 2012 & II & Sorafenib + TACE & 45 & $\mathrm{nr}$ & $\mathrm{nr}$ & 27 \\
\hline Park et $\mathrm{al}^{46}$ & 2012 & II & Sorafenib + TACE & 50 & 44 & 84 & 20.8 \\
\hline Sieghart et al ${ }^{105, b}$ & 2012 & I & Sorafenib + TACE & 15 & 46.7 & 53.3 & 10.6 \\
\hline Bai et $\mathrm{al}^{51}$ & 2013 & ॥ & Sorafenib + TACE & 164 & 9.7 & 58.5 & 7.5 \\
\hline Chung et $\mathrm{a}^{50}$ & 2013 & II & Sorafenib + TACE & 147 & 52.4 & 91.2 & $\mathrm{nr}$ \\
\hline Duan et $\mathrm{al}^{47}$ & 2012 & II & Sorafenib + TACE/TAE ${ }^{c}$ & 52 & $\mathrm{nr}$ & $\mathrm{nr}$ & 12.0 \\
\hline
\end{tabular}

Notes: ${ }^{2}$ The primary objective of this prospective trial was evaluation of safety and tolerability of a continuous regimen of sorafenib combined with TACE; btrial stopped prematurely due to safety reasons; 'transarterial chemoperfusion in patients with pulmonary metastasis. For a better comparison of study results, efficacy according to RECIST criteria is given, as some studies used RECIST and some RECIST and modified RECIST criteria.

Adapted from Welker and Trojan. ${ }^{67}$

Abbreviations: DEB-TACE, drug eluting beads-transarterial chemoembolization; DCR, disease-control rate (complete response + partial response + stable disease [\%]); OS, overall survival (months) - may differ between studies with respect to start point (start of therapy/diagnosis); RR, response rate (complete + partial response [\%]); SIRT, selective internal radio therapy; nr, not reported; TAE, transarterial embolization; RECIST, Response Evaluation Criteria in Solid Tumors trial.

Combination With Transarterial Chemoembolization (TACE)

Performed With DC Bead and Doxorubicin for Intermediate Stage Hepatocellular Carcinoma (HCC)], a randomized Phase II trial, the combination of sorafenib with DEB-TACE in intermediate-stage $\mathrm{HCC}$ was not meaningfully superior to DEB-TACE alone in terms of time to tumor progression and overall survival. ${ }^{57}$ Moreover, the combination treatment was associated with an increased rate of toxicity, especially

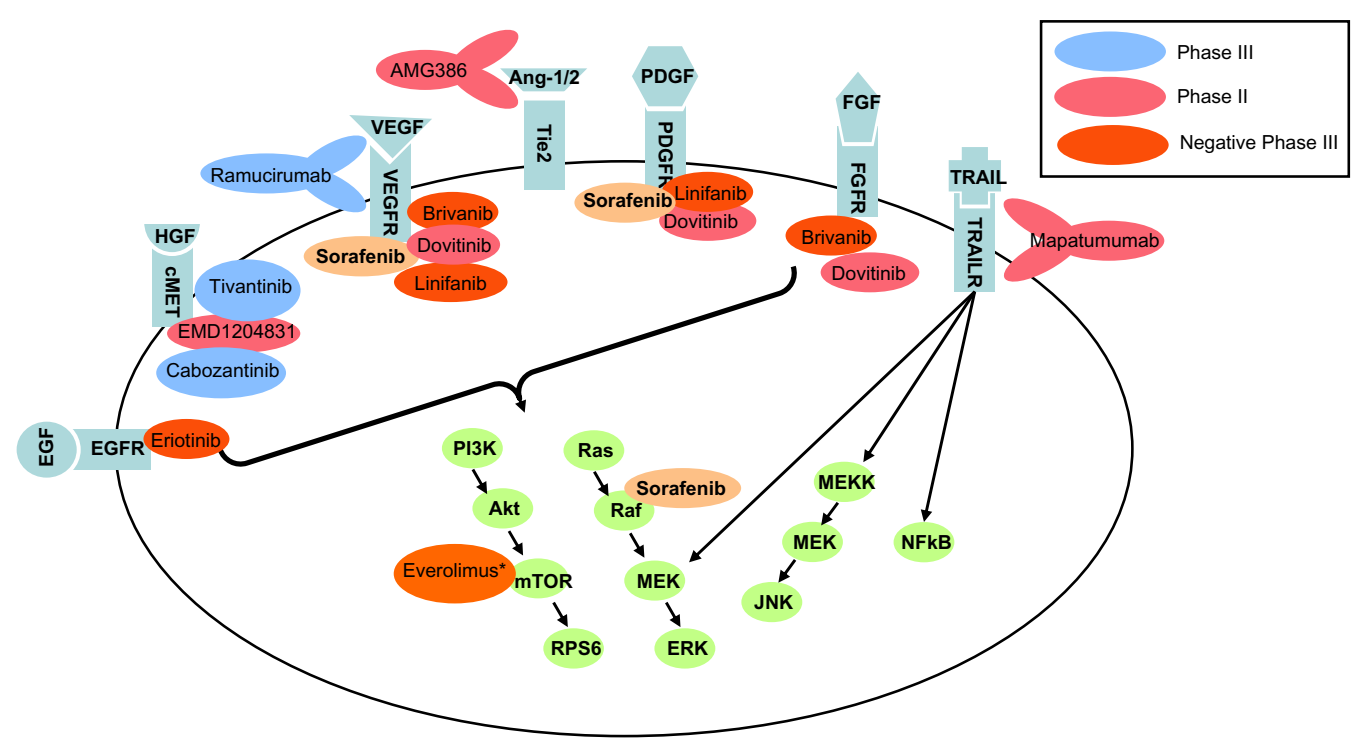

Figure 2 Molecular targets in hepatocellular carcinoma and antiangiogenic drugs according to current Phase II and Phase III studies in advanced hepatocellular carcinoma. Most agents in clinical development are antiangiogenic agents targeting angiogenesis and include different tyrosine-kinase inhibitors as well as antibodies to different cellgrowth receptors. *press release (http://www.novartis.com/newsroom/media-releases/en/2013/172/562.shtml)

Abbreviations: Ang-I/2, angiopoietin-I/2; $\operatorname{EGF(R),~epidermal~growth~factor~(receptor);~ERK,~extracellular-signal-regulated~kinase;~FGF(R),~fibroblast~growth~factor~}$ (receptor); HGF, hepatocyte growth factor; JNK, c-Jun N-terminal kinases; mTOR, mammalian target of rapamycin; NFkB, nuclear factor kappa-light-chain-enhancer of activated B cells; PDGF(R), platelet-derived growth factor (receptor); PI3K, phosphatidylinositide 3-kinases; RPS6, ribosomal protein S6; TRAIL, TNF-related apoptosis-

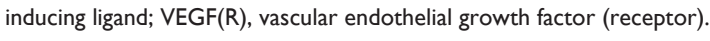


Table 3 Efficacy of combination therapy with systemic acting agents and targeted therapy in hepatocellular carcinoma, according to current Phase I-II studies.

\begin{tabular}{|c|c|c|c|c|c|c|c|c|}
\hline Author & Year & Phase & Investigational drug & $\mathbf{n}$ & $\mathbf{R R}$ & DCR & PFS/TTP & OS \\
\hline Hsu et al ${ }^{106}$ & 2010 & II & Bevacizumab/capecitabine & 45 & 9 & 51 & $2.7 / \mathrm{nr}$ & 5.9 \\
\hline Sun et $\mathrm{al}^{107}$ & 2011 & II & Bevacizumab/CapOx & 40 & 20 & 78 & $6.8 / \mathrm{nr}$ & 9.8 \\
\hline Thomas et $\mathrm{al}^{108}$ & 2009 & II & Bevacizumab/erlotinib & 40 & 25 & 67.5 & $9.0 / \mathrm{nr}$ & 15.7 \\
\hline Kaseb et al ${ }^{109}$ & 2012 & II & Bevacizumab/erlotinib & 59 & 24 & 80 & $7.2 / \mathrm{nr}$ & 13.7 \\
\hline Yau et $\mathrm{al}^{110}$ & 2012 & $\|$ & Bevacizumab/erlotinib & 10 & 0 & 0 & $1.5 / 1.8$ & 4.4 \\
\hline Philip et al"'I & 2012 & $\|$ & Bevacizumab/erlotinib & 27 & 2.1 & 44.4 & $\mathrm{nr} / 3.0$ & 9.5 \\
\hline Govindarajan et al ${ }^{1 / 2}$ & 2012 & ॥ & Bevacizumab/erlotinib & 21 & $\mathrm{nr}$ & $\mathrm{nr}$ & $\mathrm{nr} / 2.6$ & 8.3 \\
\hline Treiber et $\mathrm{al}^{113}$ & 2012 & II & Bevacizumab/everolimus & 31 & $\mathrm{nr}$ & $\mathrm{nr}$ & $\mathrm{nr} / 5.8$ & 13.3 \\
\hline Zhu et al ${ }^{114}$ & 2006 & II & Bevacizumab/GemOx & 33 & 18 & 42 & $5.3 / \mathrm{nr}$ & 9.6 \\
\hline Berlin et $\mathrm{al}^{115}$ & 2008 & $\|$ & Bortezomib/doxorubicin & 39 & 2.3 & 25.6 & $2.4 / \mathrm{nr}$ & 5.7 \\
\hline Sanoff et al ${ }^{116}$ & 2011 & $\|$ & Cetuximab/CapOx & 24 & 12.5 & 83 & $\mathrm{nr} / 4.5$ & 4.4 \\
\hline Louafi et al $\left.\right|^{117, a}$ & 2007 & ॥ & Cetuximab/GemOx & 35 & 24 & 4.5 & $\mathrm{nr} / \mathrm{nr}$ & 9.2 \\
\hline Asnacios et $118, a$ & 2008 & ॥ & Cetuximab/GemOx & 45 & 20 & 40 & $4.7 / \mathrm{nr}$ & 9.5 \\
\hline Chiorean et al ${ }^{119}$ & 2012 & II & Erlotinib/docetaxel & 14 & 0 & 46 & $3.5 / \mathrm{nr}$ & 6.7 \\
\hline Luelmo et al ${ }^{120}$ & 2012 & II & Everolimus/capcitabine & 10 & 0 & 40 & $3.4 / \mathrm{nr}$ & $\mathrm{nr}$ \\
\hline Knox et al ${ }^{121, b}$ & 2008 & ॥ & G3139/doxorubicin & 17 & 0 & 35 & $\mathrm{nr} / \mathrm{l} .8$ & 5.4 \\
\hline Yau et al ${ }^{122}$ & 2010 & $\mid / I I$ & PTK787/doxorubicin & 27 & 26 & 46 & $5.4 / \mathrm{nr}$ & 7.3 \\
\hline Petrini et al $\left.\right|^{123}$ & 2012 & $\|$ & Sorafenib/5-fluorouracil & 38 & 3 & 48 & $\mathrm{nr} / 7.6$ & 12.2 \\
\hline Richly et al ${ }^{124}$ & 2009 & I & Sorafenib/doxorubicin & 18 & 6.3 & 69 & $4.0 / n r$ & $\mathrm{nr}$ \\
\hline Abou-Alfa et al ${ }^{125, c}$ & 2010 & II & Sorafenib/doxorubicin & 96 & 4 & 77 & $6.9 / 8.6$ & 13.7 \\
\hline Dima et al ${ }^{126}$ & 2009 & II & Sorafenib/mitomycin C & 22 & 27 & 77 & $\mathrm{nr}$ & $\mathrm{nr}$ \\
\hline Prete et $\mathrm{al}^{127}$ & 2010 & $\|$ & Sorafenib/octreotide & 50 & 10 & 71 & $\mathrm{nr} / 7.0$ & 12.0 \\
\hline Abou-Alfa et al ${ }^{128}$ & 2011 & I & Sorafenib/PR-I04 & 14 & 7 & 50 & $\mathrm{nr}$ & $\mathrm{nr}$ \\
\hline Bitzer et al ${ }^{129}$ & 2012 & $1 / I I$ & Sorafenib/resminostat & 25 & d & d & d & d \\
\hline Shen et al ${ }^{\mid 30, a}$ & 2008 & ॥ & Sorafenib/tegafur-uracil & 40 & 13 & 58.3 & $3.7 / \mathrm{nr}$ & $\mathrm{nr}$ \\
\hline Hsu et ${ }^{|3|, a}$ & 2010 & II & Sorafenib/tegafur-uracil & 53 & 8 & 57 & $3.7 / \mathrm{nr}$ & 7.4 \\
\hline Hsu et $\mathrm{al}^{132}$ & 2009 & $\|$ & Thalidomide/tegafur-uracil & 43 & 9.3 & 32.6 & $1.9 / \mathrm{nr}$ & 4.6 \\
\hline Zhu et $\mathrm{al}^{133}$ & 2005 & $\|$ & Thalidomide/epirubicin & 19 & 0 & 41 & $6.0 / \mathrm{nr}$ & 6.4 \\
\hline
\end{tabular}

Notes: a Overlap of patient cohorts cannot be excluded from information provided in the abstracts; ${ }^{b}$ trial stopped due to lack of efficacy; 'trial stopped due to superiority of sorafenib; ${ }^{d}$ not reported for combination subgroup. For a better comparison of study results, efficacy according to RECIST criteria is given, as some studies used RECIST and some RECIST and modified RECIST criteria. (C) 1995-20I3 Baishideng Publishing Group Co., Limited. Adapted with permission from Welker MW, Trojan J. Anti-angiogenesis in hepatocellular carcinoma treatment: current evidence and future perspectives. Word J Gastroenterol. 201 I; 17:3075-308I. ${ }^{67}$

Abbreviations: DCR, disease-control rate (complete response + partial response + stable disease [\%]); GemOx, gemcitabine and oxaliplatin; nr, not reported; OS, overall survival (months) - may differ between studies with respect to start point (start of therapy/diagnosis); PFS/TTP, progression-free survival/time to progression (months); RR, response rate (complete + partial response [\%]); CapOx, capecitabine and oxaliplatin; RECIST, Response Evaluation Criteria in Solid Tumors trial; nr, not reported; HCC, hepatocellular carcinoma; nr, not reported.

in Caucasian patients. ${ }^{57}$ In contrast, a recent cohort study showed that DEB-TACE alone was safe and associated with a median survival of 48.6 months. Therefore DEB-TACE and also lipiodol-based TACE - seems to be an alternative treatment in patients with BCLC A-stage HCC not feasible for resection, ablation, or liver transplantation. ${ }^{58}$ Further studies still have to establish the role of sorafenib in combination with TACE.

\section{Strategies to overcome resistance to antiangiogenic treatment}

Since tumor angiogenesis is a complex process based not only on VEGF, but on a subtle interplay of intricately interweaved pathways, targeting different drivers of tumor angiogenesis might overcome antiangiogenic resistance. VEGFR2 is the critical receptor involved in tumor angiogenesis, with its activation inducing a number of other cellular modifications, resulting in tumor growth and metastases. Ramucirumab (IMC-1121B) is a fully human monoclonal antibody developed to specifically inhibit VEGFR2. Ramucirumab is currently being investigated in multiple clinical trials across a variety of tumor types, including a placebo-controlled Phase III trial in patients with HCC after failure of sorafenib. Results of this trial are expected early next year (http://clinicaltrials. gov/show/NCT01140347).

Another important regulator of vessel remodeling and maturation is the angiopoietin/Tie ligand/receptor system, which is an attractive therapeutic target in cancer. ${ }^{59}$ In theory, angiopoietin inhibitors could inhibit tumor angiogenesis efficiently, but may lack typical tyrosine-kinase receptor inhibitor-associated toxicity. Currently, the selective angiopoietin 1/2-neutralizing peptibody AMG 386 is being investigated 
in combination with sorafenib in a Phase II trial in advanced or inoperable HCC (http://www.clinicaltrials.gov/ct2/show/ NCT00872014). Completion of this study is also expected in the near future.

The most promising target in HCC is currently MET, a proto-oncogene that encodes a protein known as hepatocyte growth-factor receptor. ${ }^{60,61}$ Activation of MET signaling leads to tumor-cell growth, tumor-cell migration and invasion, and angiogenesis. ${ }^{62}$ In HCC, aberrant MET signaling is frequently found, and MET overexpression is associated with advanced tumor stage and poor prognosis. ${ }^{63-65}$ Tivantinib (ARQ 197) is an oral, selective MET tyrosine-kinase inhibitor that is developed in non-small-cell lung cancer, colorectal cancer, and HCC. ${ }^{62,66}$ Recent data from a randomized placebocontrolled Phase II study in advanced HCC after sorafenib failure demonstrated a benefit of patients with MET-high HCC only ${ }^{65}$ In this study, the median time to progression was 2.7 months in the tivantinib arm and 1.4 months in the placebo arm, and median overall survival was 7.2 months and 3.8 months, respectively, in the small group of patients with MET-high tumors. Of note, severe neutropenia developed in a substantial proportion of patients, and the dose of tivantinib was reduced from $360 \mathrm{mg}$ to $240 \mathrm{mg}$ for the further development of tivantinib in HCC. Recently, a randomized Phase III trial with tivantinib vs placebo in advanced MET-high HCC after failure of sorafenib was started (http://clinicaltrials. gov/show/NCT01755767). Cabozantinib, an oral inhibitor of RET ("rearranged during transfection"), VEGFR2, and MET is currently also being developed in a randomized Phase III trial in advanced HCC after sorafenib failure.

Further promising drugs that are under development for advanced HCC are the multiple tyrosine-kinase inhibitor dovitinib, ${ }^{134}$ the oral histone-deacetylase inhibitor resminostat (http://clinicaltrials.gov/show/NCT00943449), and RO5137382 (GC33), a humanized anti-glypican-3 monoclonal antibody (http://www.clinicaltrials.gov/ct2/show/study/ NCT01507168). An overview of current molecular targets and targeted drugs in HCC is given in Figure 2. Another approach to overcome resistance to antiangiogenic therapy is combination of targeted therapy with other systemic agents (Table 3). Currently, the efficacy and safety of these combination therapies cannot comprehensively rated, since only data from Phase I and II studies have been reported.

\section{Summary}

The multikinase inhibitor sorafenib is still the only approved drug for advanced HCC. Data concerning the combination of sorafenib with locoregional therapies are still controversial.
Multiple clinical trials are currently investigating new antiangiogenic drugs, especially in patients after failure of sorafenib. Inhibition of VEGFR2, MET, or angiopoietin, either alone or in combination with sorafenib, are promising approaches that might ultimately improve the prognosis of advanced HCC.

\section{Disclosure}

MW Welker received honoraria from Bayer Health Care. $\mathrm{J}$ Trojan received honoraria from Bayer Health Care and served on the advisory boards for Bayer Health Care, Daiichi Sankyo, Lilly Imclone, Novartis, Bristol-Myers Squib, and Roche. The authors report no other conflicts of interest in this work.

\section{References}

1. El Serag HB, Rudolph KL. Hepatocellular carcinoma: epidemiology and molecular carcinogenesis. Gastroenterology. 2007;132:2557-2576.

2. Bruix J, Llovet JM. Prognostic prediction and treatment strategy in hepatocellular carcinoma. Hepatology. 2002;35:519-524.

3. Llovet JM, Burroughs A, Bruix J. Hepatocellular carcinoma. Lancet. 2003;362:1907-1917.

4. Llovet JM, Bru C, Bruix J. Prognosis of hepatocellular carcinoma: the BCLC staging classification. Semin Liver Dis. 1999;19:329-338.

5. Bottsford-Miller JN, Coleman RL, Sood AK. Resistance and escape from antiangiogenesis therapy: clinical implications and future strategies. J Clin Oncol. 2012;30:4026-4034.

6. Forner A, Vilana R, Ayuso C, et al. Diagnosis of hepatic nodules $20 \mathrm{~mm}$ or smaller in cirrhosis: prospective validation of the noninvasive diagnostic criteria for hepatocellular carcinoma. Hepatology. 2008;47:97-104.

7. Bruix J, Sherman M. Management of hepatocellular carcinoma. Hepatology. 2005;42:1208-1236.

8. Wilhelm S, Carter C, Lynch M, et al. Discovery and development of sorafenib: a multikinase inhibitor for treating cancer. Nat Rev Drug Discov. 2006;5:835-844.

9. Avila MA, Berasain C, Sangro B, Prieto J. New therapies for hepatocellular carcinoma. Oncogene. 2006;25:3866-3884.

10. Bruix J, Sala M, Llovet JM. Chemoembolization for hepatocellular carcinoma. Gastroenterology. 2004;127:S179-S188.

11. Llovet JM, Bruix J. Unresectable hepatocellular carcinoma: metaanalysis of arterial embolization. Radiology. 2004;230:300-301.

12. De Lope CR, Tremosini S, Forner A, Reig M, Bruix J. Management of HCC. J Hepatol. 2012;56 Suppl:S75-S87.

13. Fernandez M, Semela D, Bruix J, Colle I, Pinzani M, Bosch J. Angiogenesis in liver disease. J Hepatol. 2009;50:604-620.

14. Wang B, Xu H, Gao ZQ, Ning HF, Sun YQ, Cao GW. Increased expression of vascular endothelial growth factor in hepatocellular carcinoma after transcatheter arterial chemoembolization. Acta Radiol. 2008;49:523-529.

15. Moon WS, Rhyu KH, Kang MJ, et al. Overexpression of VEGF and angiopoietin 2: a key to high vascularity of hepatocellular carcinoma? Mod Pathol. 2003;16:552-557.

16. Yamaguchi R, Yano H, Iemura A, Ogasawara S, Haramaki M, Kojiro M. Expression of vascular endothelial growth factor in human hepatocellular carcinoma. Hepatology. 1998;28:68-77.

17. Chao Y, Li CP, Chau GY, et al. Prognostic significance of vascular endothelial growth factor, basic fibroblast growth factor, and angiogenin in patients with resectable hepatocellular carcinoma after surgery. Ann Surg Oncol. 2003;10:355-362. 
18. Poon RT, Lau CP, Ho JW, Yu WC, Fan ST, Wong J. Tissue factor expression correlates with tumor angiogenesis and invasiveness in human hepatocellular carcinoma. Clin Cancer Res. 2003;9:5339-5345.

19. Poon RT, Ho JW, Tong CS, Lau C, Ng IO, Fan ST. Prognostic significance of serum vascular endothelial growth factor and endostatin in patients with hepatocellular carcinoma. Br J Surg. 2004;91:1354-1360.

20. Torimura T, Ueno T, Kin M, et al. Overexpression of angiopoietin-1 and angiopoietin-2 in hepatocellular carcinoma. J Hepatol. 2004;40:799-807.

21. Llovet JM, Ricci S, Mazzaferro V, et al. Sorafenib in advanced hepatocellular carcinoma. $N$ Engl J Med. 2008;359:378-390.

22. Abou-Alfa GK, Schwartz L, Ricci S, et al. Phase II study of sorafenib in patients with advanced hepatocellular carcinoma. J Clin Oncol. 2006;24:4293-4300.

23. Furuse J, Ishii H, Nakachi K, Suzuki E, Shimizu S, Nakajima K. Phase I study of sorafenib in Japanese patients with hepatocellular carcinoma. Cancer Sci. 2008;99:159-165.

24. Yau T, Chan P, Ng KK, et al. Phase 2 open-label study of single-agent sorafenib in treating advanced hepatocellular carcinoma in a hepatitis B-endemic Asian population: presence of lung metastasis predicts poor response. Cancer. 2009;115:428-436.

25. Worns MA, Weinmann A, Pfingst K, et al. Safety and efficacy of sorafenib in patients with advanced hepatocellular carcinoma in consideration of concomitant stage of liver cirrhosis. J Clin Gastroenterol. 2009;43:489-495.

26. Welker MW, Lubomierski N, Gog C, et al. Efficacy and safety of sorafenib in advanced hepatocellular carcinoma under daily practice conditions. J Chemother. 2010;22:205-211.

27. Rimassa L, Pressiani T, Boni C, et al. A phase II randomized dose escalation trial of sorafenib in patients with advanced hepatocellular carcinoma. Oncologist. 2013;18:379-380.

28. Cheng A, Kang Y, Lin D, et al. Phase III trial of sunitinib ( $\mathrm{Su}$ ) versus sorafenib (So) in advanced hepatocellular carcinoma (HCC). $J$ Clin Oncol. 2011;29 Suppl:4000.

29. Cainap C, Qin S, Huang WT, et al. Phase III trial of linifanib versus sorafenib in patients with advanced hepatocellular carcinoma (HCC). J Clin Oncol. 2013;31 Suppl:249.

30. French DM, Lin BC, Wang M, et al. Targeting FGFR4 inhibits hepatocellular carcinoma in preclinical mouse models. PloS One. 2012;7:e36713.

31. Cai Z, Zhang Y, Borzilleri RM, et al. Discovery of brivanib alaninate ((S)((R)-1-(4-(4-fluoro-2-methyl-1H-indol-5-yloxy)-5-methylpyrrolo[2,1-f] $[1,2,4]$ triazin-6-yloxy)propan-2-yl)2-aminopropanoate), a novel prodrug of dual vascular endothelial growth factor receptor-2 and fibroblast growth fa. J Med Chem. 2008;51:1976-1980.

32. Finn RS, Kang YK, Mulcahy M, et al. Phase II, open-label study of brivanib as second-line therapy in patients with advanced hepatocellular carcinoma. Clin Cancer Res. 2012;18:2090-2098.

33. Park JW, Finn RS, Kim JS, et al. Phase II, open-label study of brivanib as first-line therapy in patients with advanced hepatocellular carcinoma. Clin Cancer Res. 2011;17:1973-1983.

34. Llovet JM, Decaens T, Raoul JL, et al. Brivanib versus placebo in patients with advanced hepatocellular carcinoma (HCC) who failed or were intolerant to sorafenib: results from the phase 3 BRISK-PS study. J Hepatol. 2012;56 Suppl:S549.

35. Johnson P, Qin S, Park JW, et al. Brivanib (BRI) versus sorafenib (SOR) as first-line therapy in patients with unresectable, advanced hepatocellular carcinoma (HCC): results from the phase 3 BRISK-FL study. Hepatology. 2012;56 Suppl:1519-1520.

36. Ross MA, Sander CM, Kleeb TB, Watkins SC, Stolz DB. Spatiotemporal expression of angiogenesis growth factor receptors during the revascularization of regenerating rat liver. Hepatology. 2001;34:1135-1148.

37. Vogl TJ, Naguib NN, Nour-Eldin NE, et al. Review on transarterial chemoembolization in hepatocellular carcinoma: palliative, combined, neoadjuvant, bridging, and symptomatic indications. Eur J Radiol. 2009;72:505-516.
38. Llovet JM, Real MI, Montana X, et al. Arterial embolisation or chemoembolisation versus symptomatic treatment in patients with unresectable hepatocellular carcinoma: a randomised controlled trial. Lancet. 2002;359:1734-1739.

39. Poon RT, Lau C, Yu WC, Fan ST, Wong J. High serum levels of vascular endothelial growth factor predict poor response to transarterial chemoembolization in hepatocellular carcinoma: a prospective study. Oncol Rep. 2004;11:1077-1084.

40. Li X, Feng GS, Zheng CS, Zhuo CK, Liu X. Expression of plasma vascular endothelial growth factor in patients with hepatocellular carcinoma and effect of transcatheter arterial chemoembolization therapy on plasma vascular endothelial growth factor level. World $J$ Gastroenterol. 2004;10:2878-2882.

41. Shim JH, Park JW, Kim JH, et al. Association between increment of serum VEGF level and prognosis after transcatheter arterial chemoembolization in hepatocellular carcinoma patients. Cancer Sci. 2008;99:2037-2044.

42. Leelawat K, Laisupasin P, Kiatdilokrut A, et al. The effect of doxorubicin on the changes of serum vascular endothelial growth factor (VEGF) in patients with hepatocellular carcinoma after transcatheter arterial chemoembolization (TACE). J Med Assoc Thai. 2008;91:1539-1543.

43. Xiong ZP, Yang SR, Liang ZY, et al. Association between vascular endothelial growth factor and metastasis after transcatheter arterial chemoembolization in patients with hepatocellular carcinoma. Hepatobiliary Pancreat Dis Int. 2004;3:386-390.

44. Seki T, Tamai T, Ikeda K, et al. Rapid progression of hepatocellular carcinoma after transcatheter arterial chemoembolization and percutaneous radiofrequency ablation in the primary tumour region. Eur $J$ Gastroenterol Hepatol. 2001;13:291-294.

45. Erhardt A, Kolligs FT, Dollinger M, et al. First-in-men demonstration of sorafenib plus TACE for the treatment of advanced hepatocellular carcinoma - interim analysis of the SOCRATES trial. Hepatology. 2009;50 Suppl:A1080.

46. Park JW, Koh YH, Kim HB, et al. Phase II study of concurrent transarterial chemoembolization and sorafenib in patients with unresectable hepatocellular carcinoma. J Hepatol. 2012;56:1336-1342.

47. Duan F, Wang MQ, Liu FY, Wang ZJ, Song P, Wang Y. Sorafenib in combination with transarterial chemoembolization and bronchial arterial chemoinfusion in the treatment of hepatocellular carcinoma with pulmonary metastasis. Asia Pac J Clin Oncol. 2012;8:156-163.

48. Tan WF, Qiu ZQ, Yu Y, et al. Sorafenib extends the survival time of patients with multiple recurrences of hepatocellular carcinoma after liver transplantation. Acta Pharmacol Sin. 2010;31:1643-1648.

49. Qu XD, Chen CS, Wang JH, et al. The efficacy of TACE combined sorafenib in advanced stages hepatocellullar carcinoma. BMC Cancer. 2012;12:263.

50. Chung YH, Han G, Yoon JH, et al. Interim analysis of START: study in Asia of the combination of TACE (transcatheter arterial chemoembolization) with sorafenib in patients with hepatocellular carcinoma trial. Int J Cancer. 2013;132:2448-2458.

51. Bai W, Wang YJ, Zhao Y, et al. Sorafenib in combination with transarterial chemoembolization improves the survival of patients with unresectable hepatocellular carcinoma: a propensity score matching study. J Dig Dis. 2013;14:181-190.

52. Han G, Yang J, Shao G, et al. Sorafenib in combination with transarterial chemoembolization in Chinese patients with hepatocellular carcinoma: a subgroup interim analysis of the START trial. Future Oncol. 2013;9:403-410.

53. Zhao Y, Wang WJ, Guan S, et al. Sorafenib combined with transarterial chemoembolization for the treatment of advanced hepatocellular carcinoma: a large-scale multicenter study of 222 patients. Ann Oncol. 2013;24:1786-1792.

54. Dufour JF, Hoppe H, Heim MH, et al. Continuous administration of sorafenib in combination with transarterial chemoembolization in patients with hepatocellular carcinoma: results of a phase I study. Oncologist. 2010;15:1198-1204. 
55. Gao S, Yang Z, Zheng Z, et al. Doxorubicin-eluting bead versus conventional TACE for unresectable hepatocellular carcinoma: a metaanalysis. Hepatogastroenterology. 2013;60.

56. Reyes DK, Azad N, Kamel IR, et al. Phase II trial of sorafenib combined with doxorubicin eluting bead-transarterial chemoembolization (DEBTACE) for patients with hepatocellular carcinoma (HCC): interim safety and efficacy analysis. Hepatology. 2009;50 Suppl:6A-7A.

57. Lencioni R, Llovet J, Han G, et al. Sorafenib or placebo in combination with transarterial chemoembolization (TACE) with doxorubicin-eluting beads (DEBDOX) for intermediate-stage hepatocellular carcinoma (HCC): phase II, randomized, double-blind SPACE trial. J Clin Oncol. 2012;30 Suppl:LBA154.

58. Burrel M, Reig M, Forner A, et al. Survival of patients with hepatocellular carcinoma treated by transarterial chemoembolisation (TACE) using drug eluting beads. Implications for clinical practice and trial design. J Hepatol. 2012;56:1330-1335.

59. Gerald D, Chintharlapalli S, Augustin H, Benjamin L. Angiopoietin-2: an attractive target for improved antiangiogenic tumor therapy. Cancer Res. 2013;73:1649-1657.

60. Christensen JG, Burrows J, Salgia R. c-Met as a target for human cancer and characterization of inhibitors for therapeutic intervention. Cancer Lett. 2005;225:1-26.

61. Danilkovitch-Miagkova A, Zbar B. Dysregulation of Met receptor tyrosine kinase activity in invasive tumors. J Clin Invest. 2002;109: 863-867.

62. Gherardi E, Birchmeier W, Birchmeier C, Vande Woude G. Targeting MET in cancer: rationale and progress. Nat Rev Cancer. 2012;12: 89-103.

63. Kondo S, Ojima H, Tsuda H, et al. Clinical impact of c-Met expression and its gene amplification in hepatocellular carcinoma. Int J Clin Oncol. 2013;18:207-213.

64. Kaposi-Novak P, Lee JS, Gòmez-Quiroz L, Coulouarn C, Factor VM, Thorgeirsson SS. Met-regulated expression signature defines a subset of human hepatocellular carcinomas with poor prognosis and aggressive phenotype. J Clin Invest. 2006;116:1582-1595.

65. Ueki T, Fujimoto J, Suzuki T, Yamamoto H, Okamoto E. Expression of hepatocyte growth factor and its receptor, the c-met proto-oncogene, in hepatocellular carcinoma. Hepatology. 1997;25:619-623.

66. Whittaker S, Marais R, Zhu AX. The role of signaling pathways in the development and treatment of hepatocellular carcinoma. Oncogene. 2010;29:4989-5005.

67. Welker MW, Trojan J. Anti-angiogenesis in hepatocellular carcinoma treatment: current evidence and future perspectives. Word $J$ Gastroenterol. 2011;17:3075-3081.

68. O’Neil BH, Williams-Goff LW, Kauh J, et al. A phase II study of AZD6244 in advanced or metastatic hepatocellular carcinoma. J Clin Oncol. 2009;27 Suppl:e15574.

69. Schwartz JD, Schwartz M, Lehrer D, et al. Bevacizumab in unresectable hepatocellular carcinoma (HCC) for patients without metastasis and without invasion of the portal vein. J Clin Oncol. 2006; $24: 4144$.

70. Siegel AB, Cohen EI, Ocean A, et al. Phase II trial evaluating the clinical and biologic effects of bevacizumab in unresectable hepatocellular carcinoma. J Clin Oncol. 2008;26:2992-2998.

71. Boige V, Malka D, Bourredjem A, et al. Efficacy, safety, and biomarkers of single-agent bevacizumab therapy in patients with advanced hepatocellular carcinoma. Oncologist. 2012;17:1063-1072.

72. Kim GP, Mahoney MR, Szydlo D, et al. An international, multicenter phase II trial of bortezomib in patients with hepatocellular carcinoma. Invest New Drugs. 2012;30:387-394.

73. Gruenwald V, Wilkens L, Gebel M, et al. A phase II open-label study of cetuximab in unresectable hepatocellular carcinoma: final results. J Clin Oncol. 2007;25 Suppl:4598.

74. Zhu AX, Stuart K, Blaszkowsky LS, et al. Phase 2 study of cetuximab in patients with advanced hepatocellular carcinoma. Cancer. 2007;110:581-589.

75. Philip PA, Mahoney MR, Allmer C, et al. Phase II study of erlotinib (OSI-774) in patients with advanced hepatocellular cancer. J Clin Oncol. 2005;23:6657-6663.
76. Thomas MB, Chadha R, Glover K, et al. Phase 2 study of erlotinib in patients with unresectable hepatocellular carcinoma. Cancer. 2007;110:1059-1067.

77. Shiah HS, Chen CY, Dai CY, et al. Randomised clinical trial: comparison of two everolimus dosing schedules in patients with advanced hepatocellular carcinoma. Aliment Pharmacol Ther. 2013;37:62-73.

78. Zhu AX, Abrams TA, Miksad R, et al. Phase 1/2 study of everolimus in advanced hepatocellular carcinoma. Cancer. 2011;117:5094-5102.

79. O’Dwyer PJ, Giantonio BJ, Levy DE, Fitzgerald DB, Benson AB. Gefitinib in advanced unresectable hepatocellular carcinoma: results from the Eastern Cooperative Oncology Group's study E1203. J Clin Oncol. 2006;24 Suppl:4143.

80. Lin AY, Fisher GA, So S, Tang C, Levitt L. Phase II study of imatinib in unresectable hepatocellular carcinoma. Am J Clin Oncol. 2008;31:84-88.

81. Bekaii-Saab T, Markowitz J, Prescott N, et al. A multi-institutional phase II study of the efficacy and tolerability of lapatinib in patients with advanced hepatocellular carcinomas. Clin Cancer Res. 2009;15: 5895-5901.

82. Ramanathan RK, Belani CP, Singh DA, et al. A phase II study of lapatinib in patients with advanced biliary tree and hepatocellular cancer Cancer Chemother Pharmacol. 2009;64:777-783.

83. Toh HC, Chen PJ, Carr BI, et al. Phase 2 trial of linifanib (ABT-869) in patients with unresectable or metastatic hepatocellular carcinoma. Cancer. 2013;119:380-387.

84. Rizell M, Andersson M, Cahlin C, Hafstrom L, Olausson M, Lindner P. Effects of the mTOR inhibitor sirolimus in patients with hepatocellular and cholangiocellular cancer. Int J Clin Oncol. 2008;13:66-70.

85. Cheng AL, Kang YK, Chen Z, et al. Efficacy and safety of sorafenib in patients in the Asia-Pacific region with advanced hepatocellular carcinoma: a phase III randomised, double-blind, placebo-controlled trial. Lancet Oncol. 2009;10:25-34.

86. Kudo M, Imanaka K, Chida N, et al. Phase III study of sorafenib after transarterial chemoembolisation in Japanese and Korean patients with unresectable hepatocellular carcinoma. Eur J Cancer. 2011;47:2117-2127.

87. Hoda D, Catherine C, Strosberg J, et al. Phase II study of sunitinib malate in adult pts (pts) with metastatic or surgically unresectable hepatocellular carcinoma (HCC). Presented at: 2008 Gastrointestinal Cancers Symposium; January 25-27, 2008; Orlando, FL.

88. Zhu AX, Sahani DV, Duda DG, et al. Efficacy, safety, and potential biomarkers of sunitinib monotherapy in advanced hepatocellular carcinoma: a phase II study. J Clin Oncol. 2009;27:3027-3035.

89. Faivre S, Raymond E, Boucher E, et al. Safety and efficacy of sunitinib in patients with advanced hepatocellular carcinoma: an open-label, multicentre, phase II study. Lancet Oncol. 2009;10:794-800.

90. Koeberle D, Montemurro M, Samaras P, et al. Continuous sunitinib treatment in patients with advanced hepatocellular carcinoma: a Swiss Group for Clinical Cancer Research (SAKK) and Swiss Association for the Study of the Liver (SASL) multicenter phase II trial (SAKK 77/06). Oncologist. 2010;15:285-292.

91. Wörns MA, Schuchmann M, Düber C, Otto G, Galle PR, Weinmann A. Sunitinib in patients with advanced hepatocellular carcinoma after progression under sorafenib treatment. Oncology. 2010;79:85-92.

92. Barone C, Basso M, Biolato M, et al. A phase II study of sunitinib in advanced hepatocellular carcinoma. Dig Liver Dis. Epub February 11, 2013

93. Pinter M, Wichlas M, Schmid K, et al. Thalidomide in advanced hepatocellular carcinoma as antiangiogenic treatment approach: a phase I/II trial. Eur J Gastroenterol Hepatol. 2008;20:1012-1019.

94. Santoro A, Simonelli M, Rodriguez-Lope C, et al. A phase-1b study of tivantinib (ARQ 197) in adult patients with hepatocellular carcinoma and cirrhosis. Br J Cancer. 2013;108:21-24.

95. Santoro A, Rimassa L, Borbath I, et al. Tivantinib for second-line treatment of advanced hepatocellular carcinoma: a randomised, placebocontrolled phase 2 study. Lancet Oncol. 2013;14:55-63.

96. Kanai F, Yoshida H, Tateishi R, et al. A phase I/II trial of the oral antiangiogenic agent TSU-68 in patients with advanced hepatocellular carcinoma. Cancer Chemother Pharmacol. 2011;67:315-324. 
97. Hsu C, Yang TS, Huo TI, et al. Vandetanib in patients with inoperable hepatocellular carcinoma: a phase II, randomized, double-blind, placebo-controlled study. J Hepatol. 2012;56:1097-1103.

98. Britten CD, Gomes AS, Wainberg ZA, et al. Transarterial chemoembolization plus or minus intravenous bevacizumab in the treatment of hepatocellular cancer: a pilot study. BMC Cancer. 2012;12:16.

99. Buijs M, Reyes DK, Pawlik TM, et al. Phase 2 trial of concurrent bevacizumab and transhepatic arterial chemoembolization in patients with unresectable hepatocellular carcinoma. Cancer. 2013;119: 1042-1049.

100. Pawlik TM, Reyes DK, Cosgrove D, Kamel IR, Bhagat N, Geschwind J-FH. Phase II trial of sorafenib combined with concurrent transarterial chemoembolization with drug-eluting beads for hepatocellular carcinoma. J Clin Oncol. 2011;29:3960-3967.

101. Cabrera R, Pannu DS, Caridi J, et al. The combination of sorafenib with transarterial chemoembolisation for hepatocellular carcinoma. Aliment Pharmacol Ther. 2011;34:205-213.

102. Chow PK, Poon D, Win KM, et al. Multicenter phase II study of SIR-sphere plus sorafenib as first-line treatment in patients with nonresectable hepatocellular carcinoma: the Asia-Pacific Hepatocellular Carcinoma Trials Group Protocol 05 (AHCC05). J Clin Oncol. 2010;28 Suppl:4072.

103. Erhardt A, Kolligs FT, Dollinger M, et al. Sorafenib plus TACE for the treatment of advanced hepatocellular carcinoma - final results of the SOCRATES trial. J Clin Oncol. 2011;29 Suppl:4107.

104. Wu JB, Xu GJ, Lu YS, et al. Efficacy of transcatheter arterial chemoembolization (TACE) combined with sorafenib in the treatment of advanced hepatocellular carcinoma. Afr J Pharm Pharmacol. 2012;6:2515-2519.

105. Sieghart W, Pinter M, Reisegger M, et al. Conventional transarterial chemoembolisation in combination with sorafenib for patients with hepatocellular carcinoma: a pilot study. Eur Radiol. 2012;22: 1214-1223.

106. Hsu CH, Yang TS, Hsu C, et al. Efficacy and tolerability of bevacizumab plus capecitabine as first-line therapy in patients with advanced hepatocellular carcinoma. Br J Cancer. 2010;102:981-986.

107. Sun W, Sohal D, Haller DG, et al. Phase 2 trial of bevacizumab, capecitabine, and oxaliplatin in treatment of advanced hepatocellular carcinoma. Cancer. 2011;117:3187-3192.

108. Thomas MB, Morris JS, Chadha R, et al. Phase II trial of the combination of bevacizumab and erlotinib in patients who have advanced hepatocellular carcinoma. J Clin Oncol. 2009;27:843-850.

109. Kaseb AO, Garrett-Mayer E, Morris JS, et al. Efficacy of bevacizumab plus erlotinib for advanced hepatocellular carcinoma and predictors of outcome: final results of a phase II trial. Oncology. 2012;82:67-74.

110. Yau T, Wong H, Chan P, et al. Phase II study of bevacizumab and erlotinib in the treatment of advanced hepatocellular carcinoma patients with sorafenib-refractory disease. Invest New Drugs. 2012;30: 2384-2390.

111. Philip PA, Mahoney MR, Holen KD, et al. Phase 2 study of bevacizumab plus erlotinib in patients with advanced hepatocellular cancer. Cancer. 2012;118:2424-2430.

112. Govindarajan R, Siegel E, Makhoul I, Williamson S. Bevacizumab and erlotinib in previously untreated inoperable and metastatic hepatocellular carcinoma. Am J Clin Oncol. 2012;36:254-257.

113. Treiber G, Wex T, Schneider G, et al. Treatment of advanced or metastatic hepatocellular cancer (HCC): final clinical results of a single-arm phase II study of bevacizumab and everolimus. J Clin Oncol. 2012; 30 Suppl:4107.

114. Zhu AX, Blaszkowsky LS, Ryan DP, et al. Phase II study of gemcitabine and oxaliplatin in combination with bevacizumab in patients with advanced hepatocellular carcinoma. J Clin Oncol. 2006;24: 1898-1903.

115. Berlin JD, Powell ME, Su Y, et al. Bortezomib (B) and doxorubicin (dox) in patients (pts) with hepatocellular cancer (HCC): a phase II trial of the Eastern Cooperative Oncology Group (ECOG 6202) with laboratory correlates. J Clin Oncol. 2008;26 Suppl:4592.
116. Sanoff H, Bernard S, Goldberg R, et al. Phase II study of capecitabine, oxaliplatin, and cetuximab for advanced hepatocellular carcinoma. Gastrointest Cancer Res. 2011;4:78-83.

117. Louafi S, Boige V, Ducreux M, et al. Gemcitabine plus oxaliplatin (GEMOX) in patients with advanced hepatocellular carcinoma (HCC): results of a phase II study. Cancer. 2007;109:1384-1390.

118. Asnacios A, Fartoux L, Romano O, et al. Gemcitabine plus oxaliplatin (GEMOX) combined with cetuximab in patients with progressive advanced stage hepatocellular carcinoma: results of a multicenter phase 2 study. Cancer. 2008;112:2733-2739.

119. Chiorean EG, Ramasubbaiah R, Yu M, et al. Phase II trial of erlotinib and docetaxel in advanced and refractory hepatocellular and biliary cancers: Hoosier Oncology Group GI06-101. Oncologist. 2012;17:13.

120. Luelmo S, Osanto S, Weij1 N. Phase II study of everolimus and capecitabine in patients with locally advanced or metastatic hepatocellular carcinoma (HCC). Results of the first 10 patients included. Ann Oncol. 2012;23 Suppl:1674.

121. Knox JJ, Chen XE, Feld R, et al. A phase I-II study of oblimersen sodium (G3139, Genasense) in combination with doxorubicin in advanced hepatocellular carcinoma (NCI \# 5798). Invest New Drugs. 2008;26:193-194.

122. Yau T, Chan P, Pang R, Ng K, Fan ST, Poon RT. Phase 1-2 trial of PTK787/ZK222584 combined with intravenous doxorubicin for treatment of patients with advanced hepatocellular carcinoma: implication for antiangiogenic approach to hepatocellular carcinoma. Cancer. 2010;116:5022-5029.

123. Petrini I, Lencioni M, Ricasoli M, et al. Phase II trial of sorafenib in combination with 5-fluorouracil infusion in advanced hepatocellular carcinoma. Cancer Chemother Pharmacol. 2012;69:773-780.

124. Richly H, Schultheis B, Adamietz IA, et al. Combination of sorafenib and doxorubicin in patients with advanced hepatocellular carcinoma: results from a phase I extension trial. Eur J Cancer. 2009;45: $579-587$.

125. Abou-Alfa GK, Johnson P, Knox JJ, et al. Doxorubicin plus sorafenib vs doxorubicin alone in patients with advanced hepatocellular carcinoma: a randomized trial. JAMA. 2010;304: 2154-2160.

126. Dima G, Lucia M, La Gattuta G, et al. Perspective phase II study of combination sorafenib plus mitomycin-c in the treatment of advanced hepatocellular carcinoma (HCC). Ann Oncol. 2009;19 Suppl:49.

127. Prete SD, Montella L, Caraglia M, et al. Sorafenib plus octreotide is an effective and safe treatment in advanced hepatocellular carcinoma: multicenter phase II SoLAR study. Cancer Chemother Pharmacol. 2010;66:837-844.

128. Abou-Alfa GK, Chan SL, Lin CC, et al. PR-104 plus sorafenib in patients with advanced hepatocellular carcinoma. Cancer Chemother Pharmacol. 2011;68:539-545.

129. Bitzer M, Horger M, Ganten T, et al. Efficacy, safety, tolerability, and PK of the HDAC inhibitor resminostat in sorafenibrefractory hepatocellular carcinoma (HCC). J Clin Oncol. 2012; 30 Suppl:4115.

130. Shen Y, Shao Y, Hsu C, et al. Phase II study of sorafenib plus tegafur/ uracil (UFT) in patients with advanced hepatocellular carcinoma (HCC). J Clin Oncol. 2008;26 Suppl:15664.

131. Hsu CH, Shen YC, Lin ZZ, et al. Phase II study of combining sorafenib with metronomic tegafur/uracil for advanced hepatocellular carcinoma. J Hepatol. 2010;53:126-131.

132. Hsu C, Lin Z, Lee K, et al. A phase II trial of thalidomide plus tegafur/ uracil for patients with advanced/metastatic hepatocellular carcinoma (HCC): final report. J Clin Oncol. 2009;27 Suppl:15533.

133. Zhu AX, Fuchs CS, Clark JW, et al. A phase II study of epirubicin and thalidomide in unresectable or metastatic hepatocellular carcinoma. Oncologist. 2005;10:392-398. 
134. Tai WT, Cheng AL, Shiau CW, et al. Dovitinib induces apoptosis and overcomes sorafenib resistance in hepatocellular carcinoma through SHP-1-mediated inhibition of STAT3. Mol Cancer Ther. 2012;11:452-463.
135. Zhu AX, Rosmorduc O, Evans J, et al. SEARCH: a phase III, randomized, double-blind, placebo-controlled trial of sorafenib plus erlotinib in patients with hepatocellular carcinoma (HCC). Ann Oncol. 2012;23 Suppl:LBA2.

\section{Publish your work in this journal}

Cancer Management and Research is an international, peer-reviewed open access journal focusing on cancer research and the optimal use of preventative and integrated treatment interventions to achieve improved outcomes, enhanced survival and quality of life for the cancer patient The journal welcomes original research, clinical \& epidemiological studies, reviews \& evaluations, guidelines, expert opinion \& commentary, case reports \& extended reports. The manuscript management system is completely online and includes a very quick and fair peerreview system, which is all easy to use. Visit http://www.dovepress.com/ testimonials.php to read real quotes from published authors.

Submit your manuscript here: http://www.dovepress.com/cancer-management-and-research-journal 